\title{
The Urban Public Space as The Natural Space for Women
}

\author{
Hazhir Rasoulpour ${ }^{1 *}$, Iraj Etessam ${ }^{2}$ and Arsalan Tahmasebi ${ }^{3}$ \\ ${ }^{1}$ Department of Architecture, Sanandaj Branch, Islamic Azad University, Sanandaj, Iran \\ ${ }^{2}$ Department of Architecture, Tehran Branch, Islamic Azad University, Science and Research Branch of Tehran, Tehran, Iran \\ ${ }^{3}$ Department of Architecture, Sanandaj Branch, Islamic Azad University, Sanandaj, Iran
}

*Corresponding author: Hazhir Rasoulpour, Department of Architecture, Sanandaj Branch,

Received Date: July 12, 2019

Islamic Azad University, Sanandaj, Iran.

Published Date: July 25, 2019

\begin{abstract}
In this Article, explored urban public spaces and present a gendered perspective on women in public space, planning policies and urban theories. The Research referred to the scholarly literature on gendered and non-gendered typologies of urban public space to move towards. The argument about women and the urban public space.
\end{abstract}

Keywords: Urban public space; Natural space; Women; Urban design

\section{Introduction}

The phenomenon of public space has evolved through time in different urban fabrics, civilizations, political settings and the urban design practices throughout the world. The urban public space has been under the lens of many different scholars who have extensively studied and tried to decipher the nature of the urban public space along its historic timeline [1-5].

While these studies have laid out typologies, forms, functions, and dimensions of urban public space and acknowledged the stratification of classes and rise of industrialism with respect to public spaces, they have typically lacked sociological lens which acknowledges the issue of gender and gendered experience in their studies. Political, philosophical and sociological lenses to study the nature of public spaces have been pursued by theorists and philosophers like Jane Jacobs [6] Hannah Arendt [7], Hanna Pitkin (Pitkin, 1981) Gerda Wekerle [8] and many more [9-14] giving priority to study the public space in light of women's rights, empowerment, feminist theories and research methodologies.

Space, Time and The Nature of The Urban Public Space

Early examples like the Greek Agora or the Roman Forum followed the aesthetic sensibilities of the privileged power bearers, and women, typically not having this privilege, were not allowed to participate actively in political life. Even 'noble' women's presence was not expected in the Agora, nor their attendance in the socio-cultural activities associated with it. Public spaces in the medieval times developed as a response to the necessary revival of the marketplace for trade expansion and growth of towns [4]. As the marketplaces grew in cities, many European cities like London, Venice, Rome contained civic squares or Piazzas adjacent to their town halls and cathedrals. As urban theorist Mark Girouard mentions, the idea of a piazza expressing civic dignity and therefore unsuitable for commercial activities was preserved into the advent of the fifteenth century in European towns [15].

The fifteenth-century notion of urban public space conceived the built environment of the urban public plazas to be of grandeur, taking a shift from organically naturally evolving public spaces towards being formally designed and carefully planned places by the renaissance period [2] (p. 55). Women's place in these spaces was limited to socializing almost always accompanied by men. The perspectives towards women in such spaces reduced her body to an objective value and assigned it to the man she was accompanying. Such notions reflected the position of women in the society of the time.

Renaissance squares like St. Peters in Rome or the Place de la Concorde in Paris were the main spaces of assembly places 
which celebrated civic pride, wealth and monumental iconism, representing the city identity [2]. Designing residential quarters around the squares was a popular pattern seen in London where the semi-public character and ability to restrict public access, gained admiration. The public plaza in later centuries developed as a main central common with multiple activities accompanied by arcades of important buildings and meeting houses. This kind of Commons was famous in cities like Philadelphia, San Francisco, New Orleans, etc. The street too evolved as a public space in a way to cater to transportation and vehicular access. Class prejudice and the emphasizing of the rich and the poor was a divide that Mumford had acknowledged prevalent in this kind of new streets. As Wekerle [8] points out, women's exclusive identification with the family and the "weaker" sex, not strong enough to associate with strangers in the new city life in coffee houses, cafes, restaurants, clubs, and pedestrian parks emerged in the eighteenth century, put them at risk when in these places. The presence of women in such spaces was a provocation and could incite violence or anger, thereby limiting women's accessibility to public space and their freedom in cities. In cities, a difference was also seen amongst the economic classes where the divide between private household life and the public street presence was different for the working-class women and the middle class or rich women but nevertheless, both had limited access to public spaces without fear of violence or assault.

In her book City of Women: Sex and class in New York, 19891860, Stansell (Stansell, 1987) notes that working women in the ninetieth century did participate in activities that involved working for their livelihoods and thus their access was not limited to private spheres.

However, their ventures were not completely undeterred by the perception of their presence in public spaces by men. While access to shopping gave comfort and excitement, women did not go to restaurants and clubs alone, unaccompanied by men. Even though women were limited in their participation in public social life, the activities were also very much sex or gender segregated. Stan sell even points out that their activities were a replication of their domestic responsibilities of caretaking for others through the emergence of exclusively women spaces and clubs, and their work as volunteers. As a result, even though women's activities were included in public spaces, the society perceived them through their sexuality or potential seduction which required exclusion from the public realm or their domesticity which placed them not in the public realm but at home [12].

The late nineteenth century saw Boulevards as public spaces emerging and replicating in European and American cities. This can be seen particularly in L'Enfant's Washington plan where the city's or the nation's wealth, monuments and memorials stood as achievements triumphing a plan of landscaped, arranged classical beauty into the otherwise 'messy' cityscape [4]. These spaces also celebrated almost exclusively the masculine heroisms building national heritage through public spaces around phallic monuments (obelisks), reflection pools and classically landscaped patterns on a larger than human scale.
Parks emerged in cities originally as enclosed areas containing animals to hunt [2]. Formal geometric parks in European and American cities were for the royal members of the court being seldom open to the common public. Informal parks like the St. James, Hyde Park in London, had landscaped vistas of water bodies, pathways, and grasslands thus romanticizing a countryside within the urban scenery. These parks like central park however faced restrictions, fencing off to prevent the intermingling of street life and these public spaces [2]. The reform era of the late nineteenth and the early twentieth century saw social control taking a course to shape the nature of open spaces in cities in the form not of parks but of 'playgrounds. Organized play, suggesting separate play spaces for boys, girls, toddlers emerged in New York's parks especially focusing on play equipment, gymnastic apparatus and special allocated spaces for sports like basketball, baseball, and football. This era also saw naturalization of these public parks to assimilate middle class 'American' values, educative as well as cultural, essentially to induce healthy and modern lifestyles.

Designing for leisure and leisure time gained impetus in the post-World war period and recreation facilities were assimilated into parks as public services. 1950's witnessed the rise of the new high-density suburb in America and standardization of a public space model was found to be replicated irrespective of the site location and proximity to neighborhoods or other resources [2]. This age was also the age of booming car production changing city's pattern to be more car comfortable. The middle class in American cities thus became more interested in land ownership in suburban places and thus, city's public spaces were meant and occupied by poorer and the working class. Social and racial tensions were an aspect of these spaces as conflicts related to public funds, maintenance, and bias against people of color was prevalent [2].

With the rise of commercialization and consumerism in the late 1950 's, urban forms like the farmers market, corporate plaza, festival marketplace, adventure ground, town trail, vest pocket parks, community gardens, waterfront esplanade. Carr stresses on how these diverse forms of public spaces evolved as a result of stratification of the society thus implying inequity in use of the space [2]. Communal gardens and informal local gathering gardens by creating vegetable, flower plantation was a response to the environmental movement in the early 1970s in American cities [12]. Many of these gardens can be seen in New York, Philadelphia, Chicago and other northeastern and Midwestern cities. The adventure playground was also a typology of public space that emerged in urban parts of England and Scandinavia that encouraged flexible construction of the public space by engaging children and adults in planning the spaces of their respective site. Although these kinds of spaces are more common in European cities, American cities like Irvine, Berkeley have also seen such 'play spaces'. These playgrounds have received criticism for not complying with construction standards, concerns over maintenance responsibility and not being aesthetically pleasing. As a result, there are very few examples of adventure playgrounds today. 
Pedestrian Malls and transit malls emerged as a typology to revitalize the then declining downtown in the late $1950 \mathrm{~s}$. Indoor malls like the IDS Center in Minneapolis too emerged in the downtown separating the street and the glass enclosed built environment. William Whyte referred these buildings as 'mega structures with multipurpose complex enclosed in concrete and glass' and stressed the importance of maintaining a relationship with the outdoor street [5]. Greenways or preserved green belts of open space with natural systems proliferated in addition as a response to the environmental movement initiatives to reclaim natural habitats of birds, animals and endangered ecosystems in cities and connecting them to the boundaries of cities and wilderness.

\section{Explorations Through a Gendered Lens}

All the above evolution of typologies of public spaces have developed over time and even today, cater to people's changing lifestyles and attitudes. While politics, environmentalism, economy and civil culture are factors that are widely studied to suggest better public spaces in cities, research studies, and planning policies related to women and public spaces are still very much in a minority. Karen Franck and Lynn Paxson published their work in the Human Behavior recognizing six key aspects in which public spaces should be studied and addressed [12]. Firstly, they argue that it is the socialization of women and girls which develop differently in girls because of the socio-cultural context. This can determine tendencies of use, ideas of leisure and their day to day activities. These studies when conducted through a feminist ethical lens, however, can also begin to help create positive behavioral attitudes of women in public spaces.

Secondly, household work and childcare, which were historically exclusive activities to women, up until the later part of the twentieth century was a key deterrent in women's use of public spaces in cities. Research shows that this is the case even today in America where mothers are still responsible for most of the childcare and household activities twice as much as fathers. These attitudes too should be addressed while designing public spaces. Thirdly, traveling was another factor that Franck and Paxson identified as women use more public transport and have to travel more for chores and childcare related activities. These tendencies can be under slow change even today as people are reacting to environmental lifestyle changes and improvements in public transport systems but none the less affect the environment of the public space.

Crime and fear were identified as two of the most crucial aspects, however, limiting women's use of public spaces. While extensive studies show a majority of women cite fear as the primary deterrent in avoiding public spaces, a feeling of their personal lack of competence to combat possible attacks was also reported in studies conducted in the 1980s. Crime, street harassment and fear of crime remain one of the most crucial aspects of women's use and public space today which get continuously reinforced through cultural biases, male dominated spaces, inefficient design and objectification of female bodies through media, graffiti and advertising. While surveillance is sought as a remedy in many urban places to combat violent attacks, women have reported fear of isolation and feel unsafe in dark, secluded spaces. Jane Jacobs in her book, 'Death and life of great American cities, stress on the concept of 'eyes on the streets' effectively having public spaces oriented facing the streets and by enriching the sidewalk with various activity spaces [16].

\section{Result}

In this research have elaborately cited the design theories and literature addressing the urban public space while highlighting a neglect of women's realities and experiences to occupy, belong and construct these spaces. All these factors ultimately restrict the mobility and constrain women to a far more limited manner in public space, and in the necessary activities that keep the public space active and alive. As a continuous reinforcement loop, these factors come into play to reduce female presence and engagement within such spaces ultimately serving for male-dominated spaces and acting again the very 'public' and inclusive nature of these spaces.

\section{Acknowledgement}

None.

\section{Conflict of Interest}

No conflict of interest.

\section{References}

1. Carmona M (2010) Contemporary Public Space: Critique and Classification, Part One: Critique. Journal of Urban Design 15(1): 123148.

2. Carr S (1992) Public space. Cambridge University Press.

3. Gehl J (2011) Life between buildings: using public space. Island Press.

4. Mumford L (1961) The city in history: Its origins, its transformations, and its prospects (Vol 67) Houghton Mifflin Harcourt.

5. Whyte WH (1980) The social life of small urban spaces.

6. Jacobs J (2016) The death and life of great American cities. Vintage.

7. Arendt H (2013) The human condition. University of Chicago Press, USA.

8. Wekerle GR (1980) Women in the urban environment. Signs: Journal of Women in Culture and Society 5(3): S188-S214.

9. Bondi L, Damaris R (2003) Constructing gender, constructing the urban: A review of Anglo-American feminist urban geography. Gender Place \& Culture 10(3): 229-245.

10. Boys J (1984) Women and public space.

11. Franck KA (1998) It and I: Bodies as Objects, Bodies as Subjects. Architectural Design 68: 16-19.

12. Franck KA, Paxson L (1989) Women and urban public space. In Public places and spaces, pp. 121-146.

13. Greed C (1994) Women and planning: creating gendered realities. Psychology Press, USA.

14. Rendell J (2002) The pursuit of pleasure: gender, space \& architecture in Regency London. Sandercock L (1998) Making the invisible visible: A multicultural planning history (Vol 2) Univ of California Press, USA.

15. Girouard M (1995) The English town: A history of urban life.

16. Jacobs J (1961) The uses of sidewalks: safety. The Death and Life of Great American Cities, pp. 29-54. 